\begin{tabular}{l} 
REsumo \\
Este artigo pretende tratar dos \\
principais aspectos do método cli- \\
nico e interpretativo de Melanie \\
Klein, das críticas mais contun- \\
dentes que recebeu e, pela \\
pertinência delas, do relativo \\
distanciamento ocorrido entre a \\
rígida postura de Klein e aque- \\
la dos kleinianos da atualida- \\
de. Após um fecundo exercício \\
de reflexão sobre o furor \\
interpretativo kleiniano, foi pos- \\
sível reconbecer que o brincar, \\
por si só, tem, muitas vezes, o \\
poder de permitir a elaboração \\
de determinadas tramas. Assim, \\
a interpretação saiu do foco cen- \\
tral de toda e qualquer sessão e \\
passou a ser utilizada apenas \\
nos casos em que seus recursos \\
técnicos são indispensáveis. \\
Descritores: interpretação \\
analitica; método clinico; psica- \\
nálise com crianças; Melanie \\
Klein. \\
\hline
\end{tabular}

\section{AINDA INTERPRETAMOS CRIANÇAS À MANEIRA DE MELANIE KLEIN? ${ }^{1}$}

\author{
Nivea de Fátima Gomes \\ Cassandra Pereira França
}

A

obra de Melanie Klein dificilmente deixa de suscitar críticas vigorosas ao seu estilo interpretativo, o que, por vezes, encerra o risco e o prejuízo de encobrir o mérito de sua criação técnica e de seu desenvolvimento teórico. Mesmo quando pouco se conhece de seu trabalho, sabe-se que ela deu a um certo Dick controversos esclarecimentos a respeito de suas fantasias inconscientes! $\mathrm{O}$ vigor $\mathrm{e}$ a recorrência dos questionamentos dirigidos ao trabalho de Klein lembraram a Laplanche (1988) os tempos obscuros da Inquisição, donde seu certeiro questionamento: "É preciso queimar Melanie Klein?”.

Sem sequer imaginar que um dia poderia ser colocada às bordas da fogueira, Klein sustentou, com convicção ímpar e desde suas primeiras publicações, em 1920, o alcance terapêutico de suas ousadas in-

Psicóloga. Mestre em Psicologia pela Universidade Federal de Minas Gerais (UFMG), Belo Horizonte, MG, Brasil.

- Psicóloga. Mestre em Psicologia pela Universidade Federal de Minas Gerais (UFMG), Belo Horizonte, MG, Brasil. 
terpretações, comungando com um princípio então defendido por Freud, segundo o qual conteúdos que ganham a consciência perdem sua força patogênica. Essa noção - um corolário dos passos que levaram Freud à descoberta do Inconsciente - é de tal monta que veio a incidir sobre a própria identidade da psicanálise, como é possível constatar nas palavras de Freud (1919[1918]/1996): “chamamos de psicanálise o processo pelo qual trazemos o material mental recalcado para a consciência do paciente" (p. 173). Tal proposição demarcava os limites do efeito pretendido pela interpretação: a ampliação da consciência ou a eliminação das amnésias causadas pelas defesas psíquicas. No entanto, à medida que a técnica psicanalítica de Freud se desvencilhava da sugestão, da hipnose e da reconstituição mnésica (que se mostravam tecnicamente dificultosas e limitadas do ponto de vista terapêutico), passando a utilizar "mais do material que seus pacientes lhe levavam espontaneamente e a interpretá-lo" (Chemana \& Vandermersch, 2007, p. 202), a associação livre passou a ser cada vez mais valorizada.

Conjuntamente com a associação livre, considerada a regra psicanalítica fundamental, a interpretação deslocava-se para o âmago do método freudiano. Apesar disso, Freud logo reconheceu, com muito mais acuidade do que Klein foi capaz de fazê-lo, que o alcance terapêutico desse recurso estava subordinado às regras e idiossincrasias presentes em uma análise. No caso dos adultos, o método clássico freudiano pressupunha um cenário psíquico específico: o recalcamento originário deveria ter constituído a instalação da tópica, colocando em ação no psiquismo conflitos intersistêmicos.

Qual seria, contudo, a função da interpretação na análise daqueles cuja constituição psíquica ainda estava em seu início? Precursora da psicanálise com crianças, e apesar de reconhecer as especificidades da análise infantil, Klein parece não ter-se feito essa pergunta. Aliás, nem poderia fazê-la, uma vez que tomava o inconsciente não como um efeito do recalcamento, e sim como inato, o que a levava a supor que ele podia ser precocemente analisado. Embora não o anunciasse claramente, é razoável crer que, em sua concepção, a barreira que separa os sistemas inconsciente e pré-consciente/consciente era bem mais fluida, algo comparável com a permeabilidade entre o pré-consciente e o consciente descrita pela psicanálise freudiana. E, se havia uma incógnita nessa trama, era o modo como se formava o consciente. É claro que, sob essa óptica, não a veríamos fazer como o fez Bleichmar (1993), que se pôs a "encontrar um 
ordenador que permitisse marcar tempos de analisabilidade na primeira infância situando o conflito psíquico (intersistêmico, intrassubjetivo) como eixo da analisabilidade" (p. 176). Mas, diante da constatação de que Melanie Klein não optou por esse caminho, uma pergunta surge, inevitável, procurando identificar a proveniência do êxito que ela diz ter alcançado, na análise de crianças, por via de suas interpretações: teria ele sido obtido graças à interpretação ou a despeito dela?

\section{O método interpretativo da Sra. Klein}

Quando Klein (1955[1953]/ 1991) iniciou sua prática analítica com crianças, observou que, então, se estabelecera o princípio de que "as interpretações deveriam ser dadas muito parcimoniosamente" (p. 150). De fato, os pioneiros da psicanálise infantil contentavam-se com interpretações superficiais, chegando, mesmo, à abstenção de comunicações interpretativas. Contrária a essa postura (para ela, passível de severas críticas), Klein estabelece, como a principal marca de seu método clínico, a interpretação profunda e consistente - recomendação que expressa em diversos textos, nos quais é possível ver, claramente, a influência de palavras usadas por Freud na discussão do caso Hans. 
Diferentemente de Freud, porém, Klein reconhecia que a criança, apesar de mergulhada nas relações com os objetos primários, tinha plenas condições de estabelecer, imediatamente, uma relação transferencial com um adulto estranho. Essa premissa fundamental, que, aliás, foi um de seus grandes méritos para a inauguração e difusão da psicanálise infantil, foi também aquela que tornou plausível e até mesmo imperativa a interpretação precoce (não raro, na primeira sessão), sobretudo na prevalência dos sinais de uma transferência negativa, tais como retraimento, ansiedade, desconfiança e hostilidade. Afinal, longe de avaliar a transferência negativa como evidência de insucesso ou de mera inconveniência, o método kleiniano preconizava que ela fosse tratada por meios analíticos, isto é, que fosse reconhecida e interpretada, a fim de que se criasse, dentre outros efeitos, sua modulação rumo à transferência positiva e ao estabelecimento da situação analítica.

A interpretação, portanto, não foi considerada por Klein um dos recursos que podem abrir o trabalho analítico, mas, sim, o único caminho: "na análise de crianças é só a interpretação, na minha experiência, que dá início ao processo analítico e o mantém em andamento" (Klein, 1932/1997, p. 94). Logo, antes que se afirme que Klein atropelou a ordem dos acontecimentos, interpretando antes que o vínculo transferencial positivo se consolidasse, deve-se ressaltar o fato de que ela transformou o que seria um pré-requisito da interpretação em seu efeito, ou seja, a interpretação foi considerada, ela mesma, propiciadora do vínculo analítico. Ao que parece, a razão disso encontra-se na capacidade da interpretação de desmobilizar as defesas e, assim, de dar abertura ao inconsciente e ao livre jogo entre amor e ódio que domina as relações de objeto iniciais. Desse modo,

Quando a análise já começou e uma certa quantidade de ansiedade já foi resolvida no pacientezinho por meio de interpretações, a sensação de alívio que ele experimenta como consequência disso - com frequência já após algumas sessões - o ajudará a prosseguir o trabalho. Pois, se até então não tivera nenhum incentivo para ser analisado, tem agora um insight quanto ao uso e valor do trabalho analítico, que é um motivo tão eficaz para ser analisado quanto o insight que o adulto tem a respeito da sua doença. (Klein, 1932/1997, p. 30)

Como se vê, era bastante sólida a argumentação oferecida por Klein para justificar a pertinência da interpretação, em seu papel de colocar e recolocar a análise em marcha rumo à resolução dos conflitos infantis. A autora embasava seus pontos de vista com inúmeros exemplos, ilustrativos da eficácia da interpretação dentro e fora do cenário analítico.

Segundo o referencial kleiniano, a diminuição da ansiedade é o elemento que melhor representa a direção da cura e comprova a eficácia da interpretação. Além disso, em seu rastro, traz efeitos tais como a diminuição da 
repressão e das inibições e o aumento da capacidade sublimatória.

Klein deixa bem claro que o trabalho analítico, ao interpretar para a criança o que suas brincadeiras, seus desenhos e todo o seu comportamento significam e, assim, erguer as "comportas" da repressão, libera tanto as fantasias quanto a energia dispendida para manter a repressão. Uma vez liberada, essa energia pode ser investida em novas direções, donde o incremento da capacidade sublimatória, muitas vezes atingido por meio da análise e visível no surgimento de um grande número de novos interesses.

O uso convicto da interpretação e a correlata defesa de uma análise conduzida em profundidade ajustam-se à concepção de Klein a respeito do desenvolvimento superegoico ou moral da criança. Uma das inovações da metapsicologia kleiniana é a teorização sobre o superego tirânico e precoce, cujo surgimento se daria bem antes do que tinha sido estabelecido por Freud. Entende Klein que, em termos dos objetivos analíticos, a criança só tem a ganhar se a análise conseguir, através das interpretações, abrandar a severidade do seu superego e, com isso, aliviar a pressão exercida sobre seu ego pouco amadurecido:

À medida que a análise continua, as crianças vão se tornando capazes em alguma medida de substituir os processos de repressão pelos de rejeição crítica. Isto se observa quando, num estágio posterior de suas análises, elas se mostram tão distanciadas dos impulsos sádicos que antes as governavam e a cujas interpretações opunham resistências fortíssimas, que por vezes até acham graça deles. Já ouvi crianças muito pequeninas rirem, por exemplo, da ideia de que uma vez elas realmente quiseram devorar a mamãe ou cortá-la em pedaços. (Klein, 1932/1997, p. 33)

Esse abrandamento gradativo do superego, implícito nessa citação, ocorre enquanto os objetos edipianos vão sendo introjetados ao longo da primeira infância. Para tanto, o analista deve manter uma escuta acurada voltada para o simbolismo das ações e dizeres da criança e para as manifestações do conflito edípico, que é de tão forte impacto no desenvolvimento psíquico e no decurso da análise.

Outro aspecto muito peculiar do estilo interpretativo de Klein é a linguagem usada para comunicar-se com a criança, marcada por referências a objetos parciais e a termos anatômicos e fisiológicos. Frequentemente, as interpretações evocam a imagem de uma carnificina, uma guerra, um filme de terror (onde o pai é assassinado ou assombra com ameaças de morte, o corpo materno é picado, cozinhado e comido ou destruído com armas fecais). Essa descrição 
das cenas dantescas que se passam no imaginário da criança é tão pertinente que não encontramos analistas de crianças que, mesmo sendo de outras correntes teóricas, dispensem a leitura de um livro como $A$ psicanálise de crianças. O comentário geral desses profissionais é de admiração diante da perspicácia com que Klein captava as fantasias do universo infantil. De fato, Klein estava convencida de que a linguagem que empregava era compatível com as fantasias inconscientes da criança e, também, que “em toda criança, assim como em todo adulto, apesar de toda a resistência e das defesas, há anseio e prazer pela verdade" (Segal, 1987/1996, p. 10).

Essa crença kleiniana no valor curativo da verdade acabava sendo reforçada pelo fato de que as crianças pareciam reagir muito bem ao seu estilo de comunicação. Porém, mesmo captando com prontidão as fantasias da criança, Klein, ao contrário do que julgam os críticos, não descartava a prudência, conforme podemos observar no excerto que se segue:

A análise de crianças muito pequenas tem mostrado repetidamente quantos significados diferentes pode ter um único brinquedo ou um único segmento de uma brincadeira e que só podemos inferir e interpretar o seu significado quando consideramos suas conexões mais amplas e a situação analítica em que se inserem. (Klein, 1932/1997, pp. 27-28)

Portanto, usualmente, ela não interpretava o material "até ele ter sido 
expresso em várias representações" (Klein, 1930/1997, p. 260), ou seja, até ter-se repetido em diferentes contextos e brincadeiras e se fazer acompanhar pelas palavras da criança. No entanto, o trabalho de síntese que é exigido de qualquer apresentação de material clínico não nos permite afirmar se ela apenas recomendava prudência ou se era, de fato, comedida e esperava a ocasião certa para interpretar. Seja como for, a sólida argumentação de Klein a favor do recurso interpretativo na análise de crianças, longe de equacionar as divergências relativas ao papel da interpretação, acabou por despertar uma avalanche de críticas ao seu método.

\section{Críticas ao estilo interpretativo kleiniano}

Segundo as críticas que lhe foram rendidas, Klein supervalorizava de tal modo esse recurso que incidia no equívoco do uso de interpretações precoces e excessivas, que representavam, sobretudo, uma imposição do saber e da subjetividade do analista, expressa por interpretações baseadas em um sistema simbólico predeterminado. Essas acusações recaíam, principalmente, sobre o método utilizado no tratamento de Dick: o enxerto do simbólico em seu aparelho psíquico. A despeito dos resultados admiráveis alcançados por Klein, muitos analistas, baseados nesse e em 
outros relatos de caso, fizeram críticas intransigentes ao modelo interpretativo da psicanalista, salientando a desconsideração do movimento associativo da criança, o que constituiria um desvio da regra fundamental da técnica psicanalítica. De acordo com Laplanche (1988):

É surpreendente que uma teoria que se situa tão próxima dos processos mentais mais profundos do inconsciente só tenha conseguido se traduzir num método que chega à decodificação mais estereotipada dos ditos e gestos significativos do paciente, sem considerar o movimento associativo, a referência histórica e individual, e os mil e um indícios pelos quais descobrimos se a interpretação está ou não num bom caminho. (p. 52)

Apesar de todas essas críticas serem pertinentes, pois Klein realmente fez, em alguma medida, o que lhe foi atribuído, temos de lamentar o fato de que muitas delas se tornaram até mesmo ácidas, notadamente quando vinham daqueles que leram apenas trechos isolados da obra kleiniana e que desconheciam os fundamentos teóricos que embasavam essas interpretações e, ao mesmo tempo, se reformulavam com os efeitos delas.

A questão é por demais polêmica, principalmente porque se tratava da apresentação de um método clínico novo, que buscava descobrir um acesso ao inconsciente infantil, uma vez que nem sempre é pela expressão verbal que se dão as associações das crianças. Com efeito, quem as atende sabe que elas raramente narram sonhos ou episódios angustiantes de sua vida cotidiana e que, através do discurso delas, sequer chegam ao conhecimento seus pesadelos ou fatos como a morte de entes queridos. Por esse motivo, a proposta kleiniana era a da imbricação entre as dramatizações fantasiosas e as expressões verbais.

$\mathrm{Na}$ guerra entre as escolas de psicanálise, todavia, esse assunto acabou por despertar opiniões controversas de um lado e outro da trincheira, conforme podemos acompanhar pela literatura: enquanto Santa Roza (1993) pergunta se "estaria de acordo com a inspiração freudiana esse método kleiniano que propõe pôr a descoberto o inconsciente da criança através de uma tradução imediata de brincadeiras" (pp. 121-122), Cintra e Figueiredo (2004) argumentam que tal método é "uma possibilidade - a única - de dar forma, nome e uma certa passagem para a simbolização ao irrepresentável pulsional" (p. 176). 
Embora saibamos que as críticas contundentes trouxeram rearranjos fundamentais à psicanálise kleiniana, elas, infelizmente, desestimularam o estudo sistemático de sua obra, razão pela qual alguns profissionais se valem de suas contribuições sem nem mesmo reconhecerem a autoria da técnica, a exemplo do uso que é feito do brincar como o equivalente da associação livre. Outros, ainda, no afã de entender o que está sendo comunicado pelas crianças durante o atendimento psicanalítico, dão-se ao luxo de ler apenas a casuística clínica - justamente aquela que mais polêmicas criou!

Quando nos dedicamos à leitura atenta de tais registros, imediatamente nos salta aos olhos a ausência de dados relativos aos pais das crianças, bem como aqueles referentes à anamnese. Poderíamos imaginar que tal omissão se deve ao fato de que Klein se orgulhava em afirmar que o seu interesse estava nas imagos parentais da criança, o que, aliás, contaminou a clínica de seus discípulos com a impressão de que lidar com os pais é sempre o grande peso da clínica infantil, premissa que os levou a severas restrições quanto ao número de encontros com os genitores. No entanto, a contextualização histórica desses atendimentos nos faz levantar uma hipótese bem razoável para a falta de dados anamnésicos e da lida com os pais durante o tratamento: o imperativo de resguardar a identidade das famílias, uma vez que as suas pu- blicações eram contemporâneas dos tratamentos e os pais das crianças atendidas por Klein pertenciam, frequentemente, ao meio psicanalítico, quando não, ao próprio círculo social da autora. Mas não fossem essas as condições de seu trabalho, talvez ela nem tivesse chegado às profundezas do funcionamento mental dos seres humanos nos primeiros anos de vida. Assim, cabe louvar o espírito crítico de alguns profissionais, principalmente daqueles que, após terem dedicado parte de sua vida ao estudo da obra kleiniana, acompanharam, ainda, o desenvolvimento das ideias de Lacan e de Laplanche. Esses psicanalistas, ao abrirem sua reflexão teórica a novos paradigmas, constataram a validade de antigas propostas metodológicas e puderam oferecer uma grande contribuição para a reformulação da prática da clínica infantil. Um ícone dessa postura é a psicanalista Silvia Bleichmar, que, como tantos outros psicanalistas argentinos, veio enriquecer a psicanálise brasileira com sua produção escrita, cursos e grupos de estudo. Graças a profissionais dessa estirpe, à entrada da psicanálise nas universidades e a ditames do mercado econômico, que restringia o número de sessões nos tratamentos, ocorreram mudanças significativas no exercício da clínica infantil. Se é verdade que Klein teve um séquito de discípulos que levaram seu modelo interpretativo ao extremo, daí o dito jocoso segundo o qual "pior que Klein são os 
kleinianos", é ainda verdade que essa zombaria ao fanatismo dogmático falou em favor da teoria kleiniana: após as dissensões, tornou-se imperioso, a toda uma geração de analistas, o exercício de uma reflexão que pudesse levar à reformulação de vários aspectos do método clínico de Melanie Klein. São os benefícios auferidos quando a discussão acadêmica não é tomada como um fim em si mesmo.

\section{Como interpretamos hoje}

Atualmente, a clínica psicanalítica de orientação kleiniana apresenta reformulações daqueles aspectos do método que se revelaram questionáveis. Houve um aumento da frequência de atendimentos aos pais, provocado por pelo menos dois motivos. O primeiro deles foi reflexo da influência da prática lacaniana, que, considerando a criança e seu sintoma um efeito do inconsciente dos pais, deu voz a eles, chegando até mesmo a intercalar sessões com a criança e com os pais ou, ainda, a realizar sessões conjuntas. Um outro fator que contribuiu para essa alteração foi a condição financeira das famílias, que, conforme já se disse, impôs-lhes a diminuição do número de sessões semanais. Assim, o analista foi impelido a buscar mais informações sobre a história de vida da família e do percurso que culminou no pedido de análise, bem como a fortalecer a aliança terapêutica com os pais, de quem se espera, agora, mais paciência com a lentidão dos resultados do processo analítico.

Aumentar a proximidade com os pais, e ainda com a escola e com outros especialistas que porventura atendem a criança, permite ao analista observar melhor a interação entre a história singular daquela criança e as fantasias que são desencadeadas para dar conta dos pequenos enigmas que se colocam para ela. Uma ilustração pitoresca dessa situação pode ser retirada do material clínico de uma criança com graves comprometimentos autísticos, que, depois de muitos anos de análise, inicia um processo de simbolização que lhe permite dizer que se identifica com um super-herói, "O Homem de Ferro". Além disso, sua grande dificuldade em incluir a mãe em qualquer uma de suas dramatizações ficou esclarecida para ele mesmo quando pronunciou a frase: "Eu sei quem é a mãe do Homem de Ferro: é a Mulher Invisivel?".

O exemplo citado reforça a convicção de que o analista kleiniano pode esperar pelas equações simbólicas armadas pelo próprio paciente, que com elas torna-se capaz de autointerpretar-se ou de "solicitar" uma comunicação interpretativa. No caso em pauta, a mãe da criança, apesar de comparecer às entrevistas solicitadas pela analista ou pela escola, era uma presença/ausência, pois não mostrava o seu aparelho afetivo. As- 
sim sendo, essa percepção conjunta (analista/cliente) pode ajudar a formular uma intervenção do tipo: " $\mathrm{O}$ Homem de Ferro precisa muito conhecer a mamãe dele, mas como vai fazer se ela é invisível?".

As equações simbólicas que se observam a partir do faz de conta, de desenhos, de trabalhos de modelagem e afins ficam, sobretudo, a serviço do raciocínio clínico do analista, enquanto o simbolismo veiculado por sua palavra interpretativa leva em consideração temáticas mais abrangentes, distantes daquele formato que esquadrinhava cada elemento do brincar e ditava que "isto está no lugar daquilo". Um exemplo pode ser encontrado no caso de uma paciente que se aplicava, de várias maneiras, para ficar mais próxima de sua mãe, que a havia deixado sob os cuidados de outra pessoa e mostrava-se muito inconstante do ponto de vista afetivo. Num certo momento, a criança trouxe à sessão uma revista de jogos e ficou brincando de percorrer labirintos para levar, por exemplo, um coelhinho até a cenoura. Embora tivesse idade suficiente para realizar esses jogos sem dificuldades, não os completava; ao invés disso, desenhava vários impedimentos ao longo do trajeto. Perguntar à criança "então, são assim, cheios de obstáculos, os caminhos para recuperar o que foi perdido?" foi uma possibilidade de abordar, de modo mais abstrato, a questão que a afligia. 
Sabemos que o setting analítico é sustentado tanto pela estabilidade dos fatores ambientais quanto pela constância do funcionamento emocional do analista e da qualidade de sua escuta clínica; no entanto, a singularidade de cada caso é que irá autorizar o analista a escolher a sua metodologia de intervenção. Em algumas situações, é tão satisfatório o nível de elaboração da criança que o brincar, por si só, produz efeitos que dispensam uma interpretação formal. Essa capacidade aguçada de elaboração, que permite à criança fazer comentários sobre si, indica, sem dúvida alguma, a internalização da função analítica - possibilidade que Klein não terá explorado, uma vez que fez a seguinte declaração:

Eu nunca havia visto numa análise qualquer vantagem decorrer de uma política de não interpretação. $\mathrm{Na}$ maioria dos casos em que tentei aplicar esse plano, tive logo que abandoná-lo porque se desenvolvia uma ansiedade intensa e havia o risco de interrupção da análise. (Klein, 1932/1997, p. 88)

De fato, há alguns casos em que, apesar de um bom estabelecimento das condições do setting, será apenas a interpretação que garantirá o aplacamento da angústia.

Seja como for, a interpretação permanece sendo um recurso muito estimado pelos analistas kleinianos, mas seu uso na atualidade é mais regrado que outrora, pois não há mais a urgência de empregá-la, independentemente de se haver colhido material representativo das camadas mais profundas do psiquismo desde os primeiros atendimentos. E as fantasias sádicas da criança, apesar de continuarem sendo ouvidas sem assombro pelos analistas kleinianos, recebem agora, no lugar da expressão concreta, "crua", intervenções/interpretações anunciadas numa linguagem mais abstrata e que leva em conta a história significante da criança.

Passada a ojeriza do furor interpretativo de Klein, resta-nos reconhecer que a interpretação nunca se tornou um recurso obsoleto, pois a clínica com crianças reafirma, frequentemente, o seu índice de eficácia, razão pela qual ela continua sendo empregada por analistas de diferentes correntes teóricas. Apesar dessa constatação, fica a impressão de que esse conceito da teoria da técnica psicanalítica é um rico veio de pesquisas - afinal, ainda não conseguimos delimitar qual é, precisamente, a importância da interpretação num processo de análise infantil e quais ressonâncias ela produz no psiquismo da criança em análise. Não obstante, o que é possível observar na prática clínica de muitos psicanalistas de orientação 
kleiniana é o uso parcimonioso do recurso interpretativo: ao invés da interpretação ser feita com constância, ela é reservada para aqueles momentos em que se faz imprescindível. A questão que se abre então é a de como poderíamos identificar, com certa margem de segurança, quais seriam esses momentos.

Mesmo na ausência de respostas conclusivas acerca desses questionamentos sobre o uso da interpretação, um paradoxo se faz presente: parece ser mais fácil pensar nos seus limites, ou seja, naquelas situações em que o emprego da interpretação mostra-se dispensável ou, até mesmo, inoportuno. É muito comum que o analista de crianças se veja assaltado por essas questões quando está diante de casos "difíceis", geralmente, de crianças que sofreram traumas de grande magnitude. Aí, sim, as dúvidas invadem o cenário: quando e como fazer (ou não) uma interpretação que toque nas experiências dolorosas do paciente - ainda mais se ele não as expressou espontânea e diretamente, ou se declarou, de maneira enfática, não querer falar "daquele assunto"? Fisgado por essas dúvidas, sem saber se deve ou não se reportar às vivências reais da criança ou trabalhar apenas com as suas reedições nas brincadeiras e nos movimentos transferenciais, o analista fica paralisado, presa de suas inquietações. Se, acaso, Klein presenciasse momentos como esse, provavelmente nos lembraria que, para desfazer a trama simbólica que sustenta o sintoma e envolve a história de vida da criança, quer se trate de dados factuais ou fantasiados, é necessário proceder a um rastreamento da interpretação que parta do "aqui e agora" e vá até os objetos e situações originais.

Ao que tudo indica, porém, a conduta mais frequente desse hipotético analista será a de restringir suas intervenções, por um tempo maior, aos personagens e ao roteiro da brincadeira que se desenrola na sessão. Nesse caso, falará através da boca do personagem sobre o assunto lançado pela criança (anteriormente ou naquele momento), mas, indiretamente, suas palavras poderão fazer alusão à história de vida da criança, uma vez que a temática eleita por ela não é completamente alheia à sua realidade. Poderá, também, complementar a fala do personagem com alguma intervenção em ato no interior do jogo e que, de um modo simbólico, represente a dinâmica psíquica e familiar.

Enfim, todos sabemos ser possível driblar, no dia a dia, os impasses clínicos com a ajuda do nosso feeling; mas há um grande desafio que precisa ser assumido por todos aqueles que, tal como Klein, 
não são ingênuos em acreditar que a interpretação é uma panaceia: a urgência em teorizar os alcances e limites clínicos da interpretação impostos pela prematuridade psíquica da criança e pelos movimentos fundantes de constituição das tópicas psíquicas.

DO WE STILL INTERPRET CHILDREN AS MELANIE KLEIN DID?

\section{Abstract}

This article aims to approach the main aspects of the clinical and interpretative method by Melanie Klein, from the most aggressive criticism that she has received and, once they were pertinent, from the relative distance existing between the strict attitude of Klein and the present Kleinian followers. After a fertile reflection exercise on the Kleinian interpretative passion, it is possible to recognize that playing has many times the power of allowing the elaboration of certain plots. This way, interpretation is no longer the central focus of neither all nor any session and has become used just in case its technical resources are essential.

Index terms: analytical interpretation; clinical method; psychoanalysis for children; Melanie Klein.

¿INTERPRETAMOS AÚN A LOS NIÑOS AL MODO DE MELANIE KLEIN?

\section{RESUMEN}

El artículo tiene la intención de tratar de los principales aspectos del método clinico y de interpretación de Melanie Klein, de las más fuertes críticas que recibió y, por su pertinencia, de la distancia relativa entre la rígida postura de Klein y aquella de los kleinianos en la actualidad. Después de un fructifero ejercicio de reflexión acerca del furor interpretativo, fue posible reconocer que el jugar, por si solo, tiene, muchas veces, el poder de permitir la 
elaboración de determinadas tramas. Así, la interpretación salio del foco central de toda $y$ cualquiera sesión y pasó a ser usada solamente en los casos en que sus recursos técnicos son indispensables.

Palabras clave: interpretación analítica; método clínico; psicoanálisis con niños; Melanie Klein.

\section{REFERÊNCIAS}

Bleichmar, S. (1993). A psicanálise "de fronteira": clínica psicanalítica e neogênese. In S. Bleichmar, A fundação do inconsciente: destinos da pulsão, destinos do sujeito (K. B. Behr, trad., pp. 175-204). Porto Alegre: Artes Médicas.

Chemana, R., \& Vandermersch, B. (2007). Interpretação. In Dicionário de psicanálise. (F. Settineri \& M. Fleig, trads., pp. 202-203). São Leopoldo: Unisinos.

Cintra, E. M. U., \& Figueiredo, L. C. M. (2004). Melanie Klein: estilo e pensamento. São Paulo: Escuta.

Freud, S. (1996). Linhas de progresso na terapia psicanalítica. In S. Freud, Edição standard brasileira das obras psicológicas completas de Sigmund Freud (J. Salomão, trad., Vol. 17, pp. 169-182). Rio de Janeiro: Imago. (Trabalho original publicado em 1919[1918])

Klein, M. (1991). A técnica psicanalítica através do brincar: sua história e significado. In M. Klein, Inveja e gratidão e outros trabalhos (L. P. Chaves et al., trads., pp. 149168). Rio de Janeiro: Imago. (Trabalho original publicado em 1955[1953])

Klein, M. (1997). A psicanálise de crianças (L. P. Chaves, trad.). Rio de Janeiro: Imago. (Trabalho original publicado em 1932)

Laplanche, J. (1988). É preciso queimar Melanie Klein? In J. Laplanche, Teoria da sedução generalizada e outros ensaios (pp. 5059). Porto Alegre, RS: Artes Médicas. 
Santa Roza, E. (1993). Quando brincar é dižer: a experiência psicanalítica na infância. Rio de Janeiro: Relume Dumará.

Segal, H. (1996). Nova introdução. In M. Klein, Amor, culpa e reparação e outros trabalbos (A. Cardoso, trad., pp. 9-13). Rio de Janeiro: Imago. (Trabalho original publicado em 1987)

\section{NOTA}

1 Este artigo baseia-se nos resultados da dissertação de mestrado submetida pela primeira autora, sob orientação da segunda, ao programa de Mestrado em Psicologia da Universidade Federal de Minas Gerais. Agradecemos à Coordenação de Aperfeiçoamento de Pessoal de Nível Superior (CAPES).

niveafatimapsi@yahoo.com.br Rua Antônio Alves de Paula Neto, 123 35505-000 - Divinópolis - MG - Brasil.

cassandrapfranca@gmail.com Av. André Cavalcante, 136/701 30430-110 - Belo Horizonte - MG - Brasil. 